\title{
Decifrando as dinâmicas do crime
}

Camila C. Nunes Dias. PCC: hegemonia nas prisóes e monopólio da violência. São Paulo, Saraiva, 2013. 455 páginas.

\section{Fernando Salla}

No âmbito das ciências sociais, diversos estudos foram produzidos, desde a década de 1980, na tentativa de explicar o crescimento da criminalidade no Brasil, bem como os seus efeitos sobre a vida das populaçóes urbanas e sobre os aparatos destinados à gestão do controle sobre o crime e a punição (Pinheiro, 1981; Paixão, 1988; Zaluar, 1983; Fisher e Adorno, 1987; Misse, 1999 e 2006; Adorno, 1996). O expressivo crescimento da população encarcerada, nesse período, colocou em cena também novas dinâmicas no domínio da criminalidade e nas formas de sua contenção que ampliaram os desafios para as pesquisas na área das ciências sociais no país. Uma questão instigante, por exemplo, foi a emergência de grupos criminosos organizados dentro dos ambientes prisionais, para além daquelas quadrilhas e bandos que ali sempre estiveram presentes. Tais grupos forjaram identidades a partir de componentes próprios do mundo do crime e mesclaram no seu modo de atuação práticas e referências já existentes na sociabilidade das áreas pobres e periféricas das grandes cidades. No Rio de Janeiro, o mais famoso desses grupos foi o Comando Vermelho (CV) e, em São Paulo, o Primeiro Comando da Capital (PCC). Cada um desses grupos teve, no entanto, uma trajetória própria de formação e atuação, em que pesaram as características locais dos mercados ilegais, as relações com os grupos rivais e principalmente as relaçóes com as forças repressivas. Tais grupos alteraram as dinâmicas da criminalidade tanto numa escala local como nacional, e mesmo internacional, se considerarmos o seu envolvimento com o tráfico de drogas no âmbito da América do Sul. As atividades criminais desses grupos transbordaram, portanto, os limites da prisão e passaram também a afetar diretamente a vida da população em várias áreas urbanas.

Apesar da projeção desses grupos em todas essas dimensóes, pode-se considerar que ainda são poucos os estudos no campo das ciências sociais, no 
Brasil, que se dedicaram a explicar os processos que conduziram à emergência de tais grupos, sua existência nos domínios da criminalidade e seus efeitos sobre a sociedade de uma forma geral.

O livro de Camila Nunes Dias contribui de forma relevante para a compreensão dos aspectos que colocaram o PCC em evidência no debate público nos últimos vinte anos. Cabe lembrar alguns dos principais eventos que tornaram o PCC o centro de atençóes não somente para as autoridades da área da segurança pública e justiça mas também para os pesquisadores do campo das ciências sociais: em 2001, o PCC foi o responsável por uma megarrebelião em 29 unidades prisionais do estado de São Paulo. Cerca de 30 presos foram mortos em conflitos internos e o PCC reivindicava a desativação do Anexo da Casa de Custódia de Taubaté, unidade que entáo confinava os presos considerados líderes de grupos ou "inadaptáveis". Além dessa capacidade de mobilizar simultaneamente um número considerável de unidades prisionais, o PCC ainda trazia um fenômeno novo que era a transformação dos próprios familiares em reféns-colaboradores da megarrebelião (que havia começado num domingo, dia de visita). Um segundo conjunto de acontecimentos se deu em 2006, quando o PCC desencadeou no estado de Sáo Paulo, principalmente em sua capital, uma série de atentados a bancos, supermercados, prédios públicos e ordenou o assassinato de policiais e agentes penitenciários. Além desses atentados, dezenas de ônibus foram queimados, paralisando a cidade de São Paulo. Foram três ondas de ataques que se desdobraram de maio a agosto daquele ano. Os atentados mostravam o grau de transbordamento do poder do PCC para além dos muros da prisão e uma ousadia nos ataques aos agentes públicos. Em terceiro lugar, ao longo de 2012, um amplo conflito se estabeleceu entre as forças de segurança, sobretudo a Polícia Militar, e o PCC. Em 2012, dos 6.145 homicídios ocorridos no estado de Sáo Paulo, 547 foram provocados por policiais militares e outros 17 por policiais civis em serviço, somando assim 564 homicídios, o que representou 9,2\% de todas as ocorrências. Foram 14 os policiais militares assassinados naquele ano e 2 policiais civis. Em 2011, o número de pessoas mortas em confrontos com a polícia foi de 460: portanto, em comparação com as 564 mortes de 2012, houve um aumento de $18,4 \%{ }^{1}$

Como esse grupo conseguiu alcançar tamanho poder dentro e fora das prisôes? Como se construiu essa disposição e essa capacidade de enfrentar as forças policiais? E, o mais importante, como responder a essas questóes a partir do repertório interpretativo das ciências sociais? Foram estas algumas das questôes que Camila Dias procurou responder. Seu trabalho, apresentado como tese de doutoramento em sociologia na Universidade de Sáo Paulo, parte das principais balizas teóricas disponíveis, sobretudo no terreno da sociologia, para analisar os contextos que tornaram possível a emergência do PCC e decifrar principalmente os processos sociais que conduziram à sua hegemonia sobre a massa carcerária no sistema prisional paulista, sua presença no mundo do crime e sua influência sobre as populaçóes de variados territórios urbanos.

Há que se considerar, antes de mais nada, as dificuldades inerentes para se fazer uma pesquisa sobre um grupo criminoso organizado e sobre o próprio contexto prisional. As limitaçôes e os obstáculos são consideráveis para a obtenção de documentos oficiais, para o acesso aos espaços prisionais, para o estabelecimento de contato direto com os principais atores como presos, policiais, agentes penitenciários, diretores de unidades prisionais etc. Certa facilidade na reunião de informaçōes só existiu em relaçáo a fontes representadas pela imprensa, que cada vez mais tem deixado à disposição do público em geral os arquivos de jornais e revistas para consulta. A autora recorreu, também, aos relatórios das Comissóes Parlamentares de Inquérito (CPIs), especialmente a do Tráfico de Armas (2005-2006). $\mathrm{E}$ teve acesso ainda aos depoimentos sigilosos das sessóes reservadas dessas CPIs.

A principal fonte de dados sobre o sistema penitenciário paulista, a Secretaria da Administração Penitenciária (SAP) de São Paulo, depois dos acontecimentos de maio de 2006, retirou do seu portal informaçóes básicas sobre as unidades prisionais, sob a alegação de que elas poderiam significar algum tipo de risco para a segurança pública (!). Mas, felizmente, a SAP não obstruiu o acesso da pesquisadora às prisóes e aos presos, nem $\mathrm{o}$ acesso a uma fonte igualmente rica para a compreensão das 
dinâmicas prisionais que são as sindicâncias instauradas nas próprias unidades.

O capítulo metodológico (com cerca de 40 páginas) no qual a autora apresenta todo o percurso da pesquisa é uma contribuição bastante relevante do seu trabalho para aqueles que buscam tais espaços para a realização de suas pesquisas acadêmicas. ${ }^{2} \mathrm{Ca}$ mila Dias descreve, com transparência, as estratégias e táticas a que teve que recorrer para conseguir o seu objetivo de analisar as modificaçóes no sistema prisional paulista nas últimas décadas e como, nesse contexto, o PCC conquistou a hegemonia sobre a massa carcerária. Deve-se reconhecer que nem sempre têm sido apresentados, de modo claro, por parte de muitos pesquisadores, os caminhos utilizados para lidar com esses objetos "difíceis" no campo das ciências sociais. De tal modo que não são descritos, por vezes, os percursos de aproximação e os acordos com os envolvidos para pesquisar, por exemplo, as relaçóes sociais no tráfico de drogas ou em outras atividades criminosas, ou ainda os arranjos para ter acesso às dinâmicas nos espaços de confinamento etc. Há em muitos estudos material empírico e análises que podem ser bastante interessantes, mas que deixam um nevoeiro de dúvidas para o leitor com relação ao processo de coleta das informaçôes. Nesse sentido, Camila vai numa direção oposta e descreve com objetividade os detalhes no seu caminho de pesquisa com os obstáculos e com as oportunidades que foram aparecendo. As entrevistas que realizou com presos são sem dúvida o material essencial de seu trabalho. A autora entrevistou 31 presos em três unidades prisionais e pôde extrair delas um rico conjunto de informações para sua argumentação.

Camila recorre na sua análise aos autores, nacionais e internacionais, relevantes que integram o campo do debate sobre a criminalidade, mas sobretudo sobre as prisóes, sobre as rebelióes, sobre as gangues que ali atuam. Porém, no campo teórico, a sua maior ousadia foi ir além desses autores (Sykes, 1974; Goffman, 1974; Clemmer, 1958, entre outros) e trazer para a sua construção argumentativa algumas contribuiçóes de Norbert Elias (1993). Mobilizou, para tanto, os conceitos de pacificação social, monopólio da violência, controle e autocontrole, interdependência, figuração social como ferramentas para explicar como o PCC operou uma dominação ímpar sobre a massa carcerária no sistema prisional paulista e estendeu sua influência sobre outros territórios não prisionais.

A utilização de Elias pela autora, embora inédita para explicar os processos sociais que se deram em prisões, não deixa de provocar algumas polêmicas. Elias se voltou, por exemplo, para processos sociais de longa duração para explicar a formação do Estado, o monopólio do uso da violência, a pacificaçáo social, capturando uma profunda complexidade de condiçôes objetivas e subjetivas dos indivíduos e das classes sociais. A escala temporal permite à análise de Elias conferir a permanência de formas sociais que não se desfizeram em situaçóes conjunturais, como a tendência à redução da violência no interior da sociedade mesmo depois de guerras civis ou guerras mais ampliadas. Já os processos analisados no livro aqui resenhado podem ser considerados de bem curta duração, duas décadas, envolvendo atores específicos, hierarquizados, em relaçóes sociais travadas em ambientes institucionalizados. Essa escala de curta duração sugere um plano mais conjuntural que, embora rico para a descrição empírica, traz por isso mesmo a transitoriedade, a volatilidade, a fluidez dos processos sociais. Um segundo exemplo em relação às limitaçóes do uso das análises de Elias para a conjuntura prisional diz respeito à questáo do autocontrole. Para ele, a pacificação social resulta tanto da criação de mecanismos objetivos de destituição do uso da violência por parte dos indivíduos e grupos como também da criação de formas subjetivas de pacificação através de autocontrole. Novamente, a escala temporal é decisiva no estabelecimento desse processo. No livro, no entanto, não foi analisado com maior precisão o lugar do autocontrole na configuração de uma nova ordem prisional sob a hegemonia do PCC. Este aparece como monopolizador do uso da violência sobre a massa carcerária, fazendo pairar sobre ela a ameaça direta de seu uso em caso de dissidência, sugerindo muito mais uma dominação de natureza coercitiva do que um contexto de pacificaçáo que tenha promovido processos de subjetivação na direção de uma internalização do autocontrole. 
No plano da reconstrução histórica da formação e consolidação do PCC, o trabalho constrói periodizaçôes que ajudam a compreender as principais características das diferentes fases desse grupo. Num primeiro período (de 1993 a 2001), trata-se de sua ascensão em um processo de expansão territorial, dominando gradativamente as unidades do sistema prisional paulista. Período que é marcado por um impressionante número de rebelióes e mortes entre os presos. O PCC conseguiu destruir ou anular os grupos de presos rivais, em um processo que envolvia tanto a eliminação física dos desafetos como as pressóes na administração para o desmantelamento dos demais grupos por meio de transferências ou isolamento em unidades prisionais específicas. Com isso, o PCC chegou ao final dos anos 1990 com amplo domínio sobre os presídios paulistas, depois de ter expropriado os grupos rivais de sua capacidade de uso da violência na solução de conflitos e no controle da massa carcerária. De acordo com a autora, no segundo período (de 2001 a 2006) o PCC se expande e impóe sua dominação, mesmo sob a pressão de algumas reaçôes do Estado, que criou o Regime Disciplinar Diferenciado (RDD) na tentativa de conter a expansão desse tipo de grupo no interior das prisões. Alternam-se os momentos de guerra interna com os de paz. De um modo geral, caem os números de homicídios dentro das prisóes e também o de rebelióes. De 2006 a 2012, desenha-se um terceiro momento em que o PCC exibe a sua hegemonia sobre a massa carcerária e ainda seu enraizamento e capacidade de mobilizaçáo fora das prisóes. Internamente às prisóes o $\mathrm{PCC}$ promove a "paz". Camila, nesse sentido, mostra como o PCC, para tanto, passou a proibir que os presos tivessem armas improvisadas (facas, "chuchos", porretes etc.), ao mesmo tempo que seus principais líderes colocavam-se como árbitros das disputas internas, regulando diversos aspectos da vida prisional, como a distribuição de presos pelos pavilhóes, pelos espaços de trabalho. É evidente que resistências e dissidências de presos a essa dominação eram vistas como enfrentamento e oposição, portanto tais presos não deveriam permanecer no convívio com os demais (o que os obrigava a permanecer nas alas de seguro ou então serem transferidos para unidades prisionais "neutras", ou seja, sem o domínio do PCC).
Muito desse padrão de organização próprio às prisōes foi transposto para as áreas nas quais o PCC passou a ter o controle sobre as atividades criminosas, especialmente o tráfico de drogas. Além disso, membros do PCC ou a ele identificados passaram a exercer um papel de árbitros e reguladores da vida das comunidades, interferindo em questóes como as relações familiares, as disputas interpessoais, promovendo "debates" e decidindo sobre a vida das pessoas.

Interessante notar que essa dimensão regulatória do PCC, tanto no interior como fora das prisóes, sempre se ancorou na sua capacidade e ameaça de impor a violência. Nunca o grupo deixou de reafirmar a sua identidade com o crime, e os dois estatutos $^{3}$ que ele produziu desde sua fundação mostram isso. São evidentes ali as ameaças de morte aos dissidentes ou aos que não se alinhassem às regras do "partido". Ou seja, quaisquer conteúdos morais ou mesmo religiosos que possam fazer parte do repertório discursivo desse grupo diluem-se nas dinâmicas de filiaçâo e lealdade ao crime e à organização, com possíveis soluçóes de natureza violenta. Camila Dias mostra também que não se sustenta $o$ argumento de que o grupo tenha se democratizado. Sua hierarquia sempre foi fortemente centralizada, as dissidências não são toleradas, não se pode questionar as decisões das lideranças. Uma certa flexibilização desse controle se deu não por dinâmicas pluralistas adotadas pela liderança em função de um "aperfeiçoamento" da organização, mas sim por conta das formas de repressão ao grupo (como por intermédio do RDD e investigaçôes do Ministério Público, entre outras), que acabaram por limitar os fluxos de comunicaçáo e articulação na linha de comando que existiram na década de 1990.

As autoridades, ao longo dos anos 1990, negaram a existência do PCC. Depois, nos anos 2000, veio o pior, pois reconheciam que ele existia, mas minimizavam sua presença nas prisóes, nas periferias e nas economias ilegais. A pesquisa apresentada no livro mostra a sofisticação dos processos de organizaçáo interna desse grupo criminoso e a trama de elementos de referência que o grupo representa para os presos e familiares, para o mundo do crime e das periferias. Ainda que possam ser voláteis tais arranjos, são demolidores dos argumentos das autoridades de que esse grupo não é organizado ou 
que se limite a um punhado de presos imobilizados numa unidade prisional do interior do estado de São Paulo (Presidente Wenceslau).

Em suma, o fato é que as prisóes brasileiras, com todas as suas mazelas, favoreceram a emergência de grupos como o Comando Vermelho e o PCC, assim como a sua permanência ao longo do tempo. A longeva precariedade material e humana que impera nas prisóes brasileiras, a persistente negação por parte do Estado dos direitos dos presos, já descritos na Lei de Execução Penal (de 1984), as falhas em todo o circuito de funcionamento das instituiçôes do sistema de justiça criminal que lastreiam esses déficits, tudo isso tem contribuído para que atores coletivos, como o PCC, levantem a bandeira da violação dos direitos, apontem tais falhas e se coloquem como defensores da massa carcerária, provendo inclusive as necessidades materiais dos presos e ainda se colocando como interlocutores frente às autoridades. Até a crônica prática da violência dos agentes em relação aos presos diminuiu diante desse empoderamento de grupos organizados.

De fato, a combinação de todos esses fatores levou a uma participação cada vez mais acentuada do PCC na manutenção da ordem no interior das prisões. Se a tradição de estudos sociológicos (Sykes, 1974; Goffman, 1974) indica que qualquer ordem interna em instituiçóes de confinamento sempre passa por negociaçóes, acomodaçóes entre custodiadores e internos, num jogo local de interaçóes sociais, o "caso" PCC traz componentes novos que desafiam essas clássicas análises. Mas não se trata apenas de um grupo de presos de uma unidade prisional barganhando com as autoridades locais a ordem interna, disciplina, benefícios e responsabilidades: trata-se de um coletivo que possui uma certa organização, uma certa identidade como grupo, que delineou algumas diretrizes de atuação para seus membros, que não está limitado a um gueto tanto no sentido territorial como em termos de atividades criminosas. Os efeitos desse novo jogo de relaçóes de poder são recentes na história das prisóes.

O livro, nesse sentido, contribui com suas análises, ancoradas na tradição da reflexão sociológica, para que se compreenda esse novo cenário presente sobre- tudo nas prisóes do estado de São Paulo, no qual os bandos, gangues, quadrilhas perdem espaços para a presença de um coletivo que se coloca como hegemônico diante da massa carcerária e que provoca novas formas de gestão prisional por parte das autoridades.

Num quadro mais geral, o trabalho de Camila integra a produção acadêmica de uma nova geração de pesquisadores (entre outros, Teixeira, 2009; Biondi, 2009; Marques, 2009; Godói, 2010; Shimizu, 2011) que, embora partam de pressupostos teóricos e metodológicos diferentes no campo das ciências sociais, contribuem de forma substantiva para a compreensão das dinâmicas prisionais contemporâneas no Brasil, dos grupos que ali atuam e dos efeitos que eles produzem direta ou indiretamente na vida das populaçóes urbanas.

\section{Notas}

1 Fonte: Coordenadoria de Análise e Planejamento (CAP) da Secretaria de Segurança Pública do Governo do Estado de São Paulo. Disponível em: <http://www. seguranca.sp.gov.br/novaestatistica/default.aspx $>$.

2 Talvez tenha sido uma sorte a autora ter feito a pesquisa antes de a SAP ter instituído, em abril de 2010, um Comitê de Ética em Pesquisa para o qual todos os projetos de pesquisa destinados ao sistema penitenciário de São Paulo precisam ser encaminhados. Esse procedimento tem sido bastante questionado na área das ciências sociais não só pelo crivo que a instância administrativa pode impor aos projetos, como também por terem esses comitês uma configuração estruturada na área da saúde e, portanto, com preocupaçôes que não necessariamente sejam aceitáveis quando se trata de pesquisa no âmbito das ciências sociais com temas como a criminalidade ou os aparatos de controle social.

3 O primeiro estatuto do PCC surgiu em meados dos anos de 1990, e o segundo apareceu em 2011. Ambos se destinavam a regular as formas de pertencimento dos membros do grupo ao PCC e principalmente as relaçóes hierárquicas dentro dele.

\section{BIBLIOGRAFIA}

ADORNO, S. (1996), A gestão urbana do medo e da insegurança: violência, crime e justiça penal 
na sociedade contemporânea. São Paulo, tese de livre-docência, FFLCH-USP.

BIONDI, K. (2009), Junto e misturado: imanência e transcendência no PCC. São Carlos, dissertação de mestrado, Centro de Educação e Ciências Humanas, UFSCar.

CLEMMER, D. (1958), The prison community. Nova York, Holt, Rinehart \& Winston.

ELIAS, N. (1993), O processo civilizador. Rio de Janeiro, Jorge Zahar, 2 vols.

FISHER, R. M. \& ADORNO, S. (1987), “Análise do sistema penitenciário do estado de São Paulo: o gerenciamento da marginalidade social”. São Paulo, Relatório de Pesquisa Cedec.

GODÓI, R. (2010), Ao redor e através da prisão: cartografias do dispositivo carcerário contemporâneo. São Paulo, dissertação de mestrado. FFFLCH, USP.

GOFFMAN, E. ([1961] 1974), Manicômios, prisóes e conventos. São Paulo, Perspectiva.

MARQUES, A. (2009), Crime, proceder, convivio-seguro: um experimento antropológico a partir de relaçóes entre ladróes. São Paulo, dissertação de mestrado, FFLCH, USP.

MISSE, M. (1999), Malandros, marginais e vagabundos e a acumulação social da violência no Rio de Janeiro. Rio de Janeiro, tese de doutorado. Iuperj. . (2006). Crime e violência no Brasil contemporâneo: estudos de sociologia do crime $e$ da violência urbana. Rio de Janeiro, Lúmen Júris.

PAIXÃO, A. L. (1988), "Crime, controle social e consolidação da democracia: as metáforas da cidadania”, in Fábio W. Reis e Guillermo O’Donnell (orgs.), A democracia no Brasil: dilemas e perspectivas, São Paulo, Vértice/Editora dos Tribunais.

PINHEIRO, P. S. (1981), Escritos indignados: policia, prisóes e política no Estado autoritário. São Paulo, Brasiliense.

SHIMIZU, B. (2011), Solidariedade e gregarismo nas facçóes criminosas: um estudo criminológico à luz da psicologia das massas. São Paulo, IBCCRIM (col. Monografias, 60).

SYKES, G. M. ([1958] 1974), The society of captives: a study of a maximum security prison. Nova Jersey, Princeton University Press.
TEIXEIRA, A. (2009), Prisóes da exceção: política penal e penitenciária no Brasil contemporâneo. Curitiba, Juruá.

ZALUAR, A. (1983), A máquina e a revolta. São Paulo, Brasiliense.

FERNANDO SALLA é pesquisador do Núcleo de Estudos da Violência da Universidade de Sáo Paulo. E-mail: fersalla@usp.br. 